\title{
Pelatihan Produksi dan Bauran Pemasaran Olahan Ubi Ungu di Kelurahan Malagusa Kabupaten Sorong
}

\author{
${ }^{1 *}$ Susetyowati Sofia, ${ }^{2}$ Retno Dwi Wijiastuti, ${ }^{3}$ Bekti Wiji Lestari, ${ }^{4}$ Nur Aeni Waly, ${ }^{5}$ Febry Jein \\ Andjar, ${ }^{6}$ Aprisa Rian Histiarini, ${ }^{7}$ Rais Dera Pua Rawi \\ 1,2,3,4,5.7Fakultas Ekonomi, Universitas Muhammadiyah Sorong, Indonesia \\ ${ }^{6}$ Fakultas Teknik, Universitas Muhammadiyah Sorong, Indonesia \\ *susetyowati.sofia@gmail.com
}

\begin{abstract}
Abstrak
Masyarakat merupakan pemeran penting yang memiliki posisi sebagai pelaku yang membangun aktif bukan hanya sebagai penerima yang pasif. Pemberdayaan masyarakat bertujuan agar masyarakat mampu mengenali kebutuhannya, merumuskan perencanaan dan melaksanakan pembangunan secara madiri. Kegiatan Pelatihan Produksi dan Bauran Pemasaran Olahan Ubi ini Bekerjasama antara Mahasiswa dan Dosen Fakultas Ekonomi Universitas Muhammadiyah Sorong dengan di ikuti oleh Para Ibu-Ibu Kelurahan Malagusa yang memiliki kegiatan usaha kecil dirumah maupun Ibu-ibu yang focus menjadi ibu rumah tangga. Permasalahan utama masyarakat di wilayah Kelurahan Malagusa Distrik Aimas Kabupaten sorong adalah: (1) bagaimana melatih masyarakat dikelurahan malagusa dalam pembuatan produk dari olahan ubi dan strategi pemasaran produk tersebut? (2) Bagaimana cara meningkatkan kemampuan masyarakat dalam memanfaatkan bahan pangan yang tersedia menjadi suatu produk yang memiliki nilai jual? (3) Bagaimana meningkatkan kemampuan dalam memproduksi suatu produk pangan, baik dalam tahap pengelolahan, pengemasan, serta memasarkan suatu produk. Pelaksanaan kegiatan Pengabdian Kepada Masyarakat di Kelurahan Malagusa Kabupaten Sorong telah terlaksana. Dalam hal ini telah dilakukan kegiatan sebagai berikut: (1) memberikan pengetahuan serta pengalaman kepada masyarakat kelurahan malagusa dalam mengelola bahan pangan dari olahan ubi Ungu menjadi produk yang memiliki nilai jual serta memasarkan produk menggunakan bauran pemasaran. (2) Melakukan diskusi mengenai kegiatan pengabdian tentang hal-hal yang terkait dengan produk, aspek pasar dan pemasaran. (3) Kegiatan pendampingan melakukan proses produksi, penggunaan alat, pengemasan dan pelabelan. (4) Kegiatan evaluasi setelah kegiatan pengabdian. Kualitas produk melalui produksi dan kemasan.
\end{abstract}

Kata Kunci: Pelatihan, Bauran Pemasaran, Olahan Ubi Ungu

\begin{abstract}
The People is an important actor who has a position as an active constructive actor, not just a passive recipient. Community empowerment aims to enable the community to recognize their needs, formulate plans and carry out development independently. This Sweet Potato Production and Marketing Mix Training activity is in collaboration between students and lecturers of the Faculty of Economics, Muhammadiyah University of Sorong, followed by the women of Malagusa Village who have small business activities at home and mothers who focus on being housewives. The main problems for the community in the Malagusa Village, Aimas District, Sorong Regency are: (1) how to train the people in the Malagusa village in making products from processed sweet potatoes and marketing strategies for these products? (2) How to improve the community's ability to utilize available food ingredients into a product that has a selling value? (3) How to increase the ability to produce a food product, both in the stages of processing, packaging, and marketing a product. The implementation of Community Service activities in Malagusa Village, Sorong Regency has been carried out. In this case, the following activities have been carried out: (1) providing knowledge and experience to the people of the village of Malagusa in managing food ingredients from processed purple sweet potatoes into products that have a selling value and marketing products using the marketing mix. (2) Conducting discussions about community service activities about matters related to products, market and marketing aspects. (3) Assistance activities carry out the production process, use of tools, packaging and labeling. (4) Evaluation activities after service activities. Product quality through production and packaging.
\end{abstract}

Keywords: Training, Marketing Mix, Purple Sweet Potatos 


\section{PENDAHULUAN}

Masyarakat merupakan sumber pembangunan, masyarakat sebenarnya memiliki potensi baik dari Sumber Daya Alam maupun sumber-sumber sosialnya. Masyarakat memiliki potensi tinggi yang jika di gali dan disalurkan akan menjadi energi yang besar untuk membangun. Dalam sebuah proses pemberdayaan masyarakat merupakan pemeran penting yang memiliki posisi sebagai pelaku yang membangun aktif bukan hanya sebagai penerima yang pasif. Pemberdayaan masyarakat bertujuan agar masyarakat mampu mengenali kebutuhannya, merumuskan perencanaan dan melaksanakan pembangunan secara madiri.

Kegiatan Pelatihan Produksi dan Bauran Pemasaran Olahan Ubi ini Bekerjasama antara Mahasiswa dan Dosen Fakultas Ekonomi Universitas Muhammadiyah Sorong dengan di ikuti oleh Para Ibu-Ibu Kelurahan Malagusa yang memiliki kegiatan usaha kecil dirumah maupun Ibu-ibu yang focus menjadi ibu rumah tangga. Pelatihan Produksi makanan merupakan salah satu kegiatan untuk memperkuat keterampilan masyarakat terutama isteri-isteri dan Ibu-Ibu rumah tangga. Menurut Gary dessler (2009), pelatihan merupakan proses mengajarkan kepada masyarakat tentang hal-hal yang baru ataupun yang sekarang keterampilan dasar yang mereka butuhkan untuk menjalankan pekerjaan mereka.

Ubi Merupakan salah satu bahan Baku yang dapat didapatkan dimana saja, Ubi juga memiliki banyak jenis warna dengan tekstur yang berbeda-beda. Menurut Zuraidah dan Supriati (2013) ubi ungu (Ipomoea batatas Lpoiret) merupakan salah satu bahan pangan yang tinggi zat gizi serta memiliki peluang sebagai substitusi bahan pangan utama, sehingga bila diterapkan mempunyai peran penting dalam upayah penganerakaragaman pangan dan dapat diproses menjadi aneka ragam produk yang mampu mendorong pengemangan agro-industri dalam diversifikasi pangan. Beberapa olahan Ubi yang umum dimasyarakat diantaranya kripik, gorengan, Kolak dan Ubi yang diolah hanya dengan di Kukus saja. Ubi merupakan Bahan yang banyak di minati oleh masyarakat bukan hanya karena rasanya enak akan tetapi juga mudah didapatkan dimana saja dan mudah dalam pengolahannya.

Isteri-Isteri dan Ibu-Ibu pada kelurahan Malagusa merupakan Masyarakat yang sebagian waktunya berada di rumah. Banyak dari mereka memiliki usaha kecil-kecilan seperti berjualan makanan, camilan dan lain sebagainya akan tetapi banyak pula dari mereka yang hanya mengurus rumah tangga. Berdasarkan pengakuan dari Ibu-Ibu yang ingin memiliki usaha dari rumah namun terkadang mereka tidak memiliki Ide, Keberanian dan juga Modal yang cukup untuk merealisasikannya. Bahkan dari mereka merasa Kurang Percaya Diri dalam memasarkan Produk yang mereka Buat dan hanya memasarkan melalui tetangga-tetangga mereka saja.

Permasalahan utama masyarakat di wilayah Kelurahan Malagusa Distrik Aimas Kabupaten sorong adalah: (1) bagaimana melatih masyarakat dikelurahan malagusa dalam pembuatan produk dari olahan ubi dan strategi pemasaran produk tersebut? (2) Bagaimana cara meningkatkan kemampuan masyarakat dalam memanfaatkan bahan pangan yang tersedia menjadi suatu produk yang memiliki nilai jual? (3) Bagaimana meningkatkan kemampuan dalam memproduksi suatu produk pangan, baik dalam tahap pengelolahan, pengemasan, serta memasarkan suatu produk.

\section{METODE PELAKSANAAN}

Kegiatan pelatihan kepada ibu-ibu dilaksanakan pada hari Jum'at, tertanggal 17 Desember 2021di Kantor Kelurahan Malagusa, Distrik Aimas, Kabupaten Sorong yang beralamatkan di jalan Cempedak - Jalur D. Metode pelatihan kegiatan pengabdian masyarakat ini dilakukan melalui langkah - langkah sebgai berikut:

1. Memberikan pengenalan teori dan cara membuat produk dari olahan ubi ungu, serta memberikan motivasi kepada masyarakat tentang manfaat dari ubi ungu dan cara memproduksi ubi ungu serta memasarkan produk tersebut. 


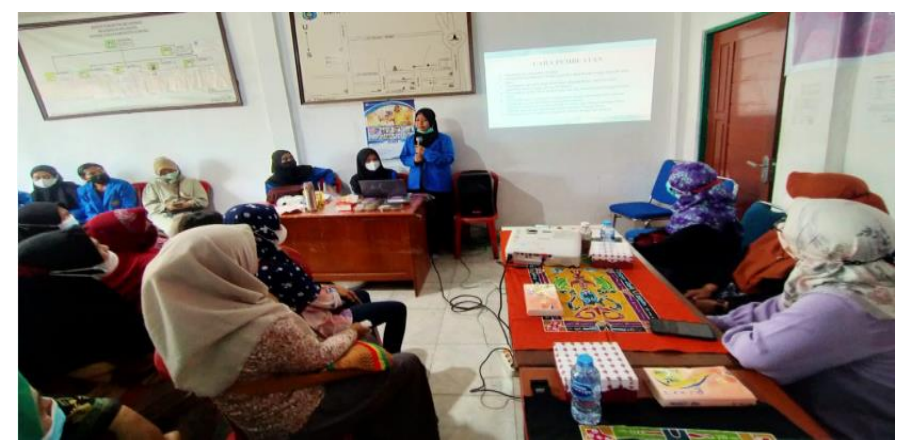

Gambar 1: Pengenalan Teori dan Cara Produksi

2. Praktik, pelatihan dan pembimbingan peserta mengenai praktik pengelola produk olahan dengan bahan dasar ubi ungu secara mandiri dengan pembimbingan, mulai dari perencanaan produksi, pemilihan bahan baku, pengenalan alat - alat produksi, pengelolahan hingga penyajian produk dalam kemasan. Menurut Heizer, 2014 dalam Kumawula, 2019 Proses yang secara kontinu sepanjang waktu berulang-ulang yang efisiensehingga menjadi ouput yang memenehuhi spesifikasi yang telah ditetapkan berdasarkan keinginan pasar.

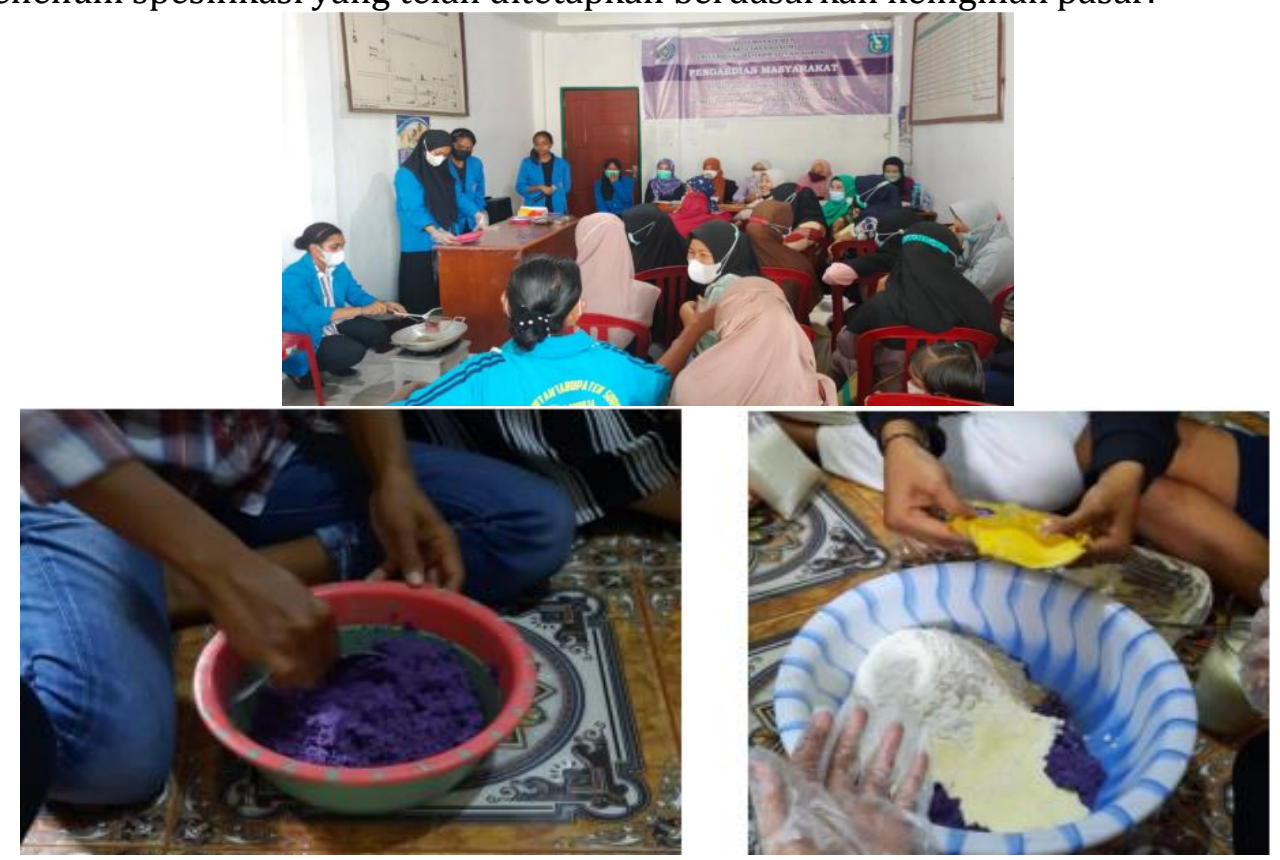

Gambar 2: Praktek Produksi

3. Pengujian tingkat kesukaan konsumen terhadap produk olahan ubi ungu dengan menggunakan 20 orang.

4. Diskusi, memperoleh Respon dari masyarakat terhadap Kegiatan Pelatihan dan pembimbingan pengolahan Bahan Baku Ubi.

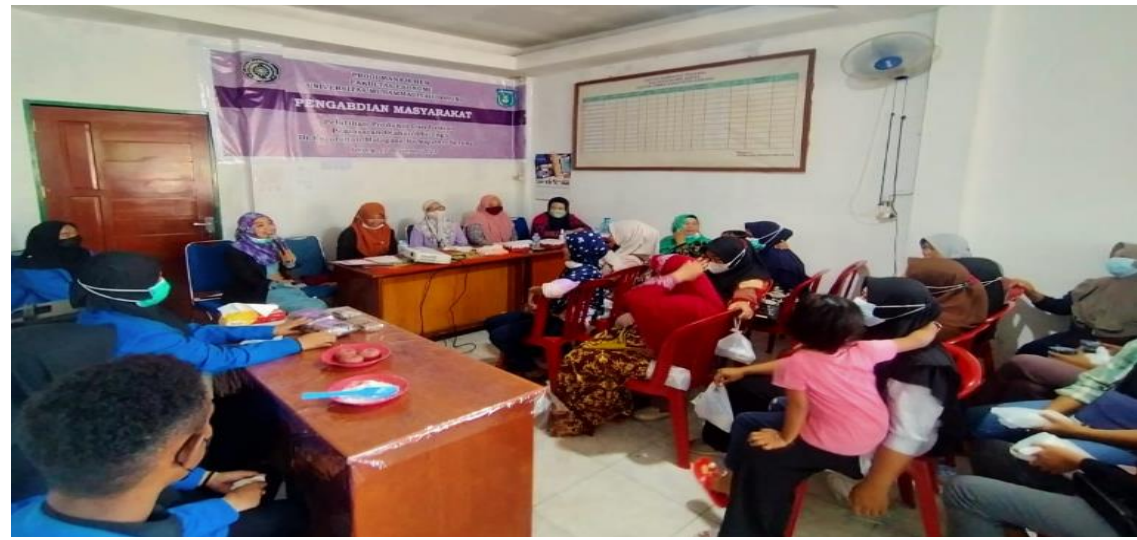

Gambar 3: Diskusi Bersama Narasumber 


\section{HASIL DAN PEMBAHASAN}

Pelaksanaan kegiatan pengabdian oleh Tim Pengabdian Masyarakat Fakultas Ekonomi dilaksanakan selama 1 (satu) hari yaitu pada hari Kamis, tanggal 17 Desember 2021 di wilayah RT 00 RW 00 Kelurahan Malagusa Kabupaten Sorong, dihadiri oleh 20 (dua puluh) peserta yang terdiri dari Bapak kepala lurah dan masyarakat setempat.

Pelaksanaan Kegiatan Pengabdian dapat diuraikan sebagai berikut:

1. Pelatihan tentang tata cara pengelolahan Produksi ubi ungu menjadi donat Ubi.

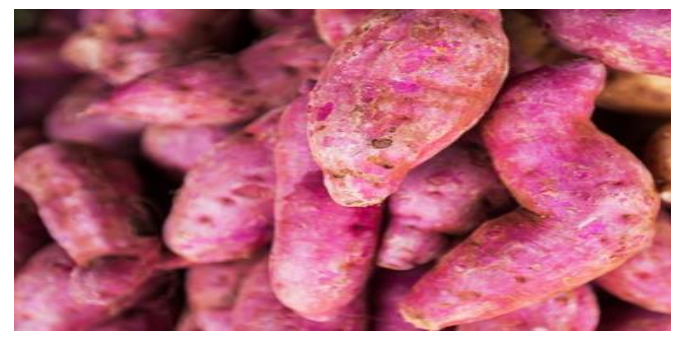

Gambar 4: Ubi Ungu

2. Pelatihan proses persiapan produksi, proses produksi hingga pengemasan dan pelabelan.

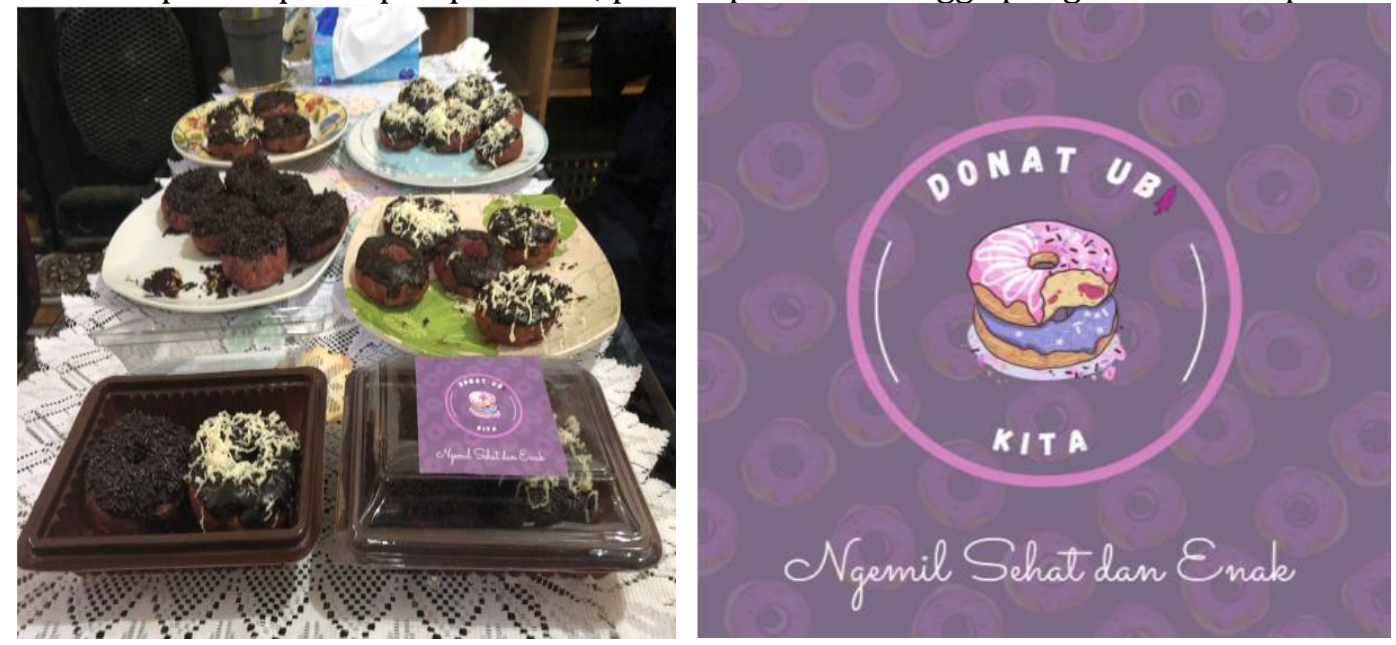

Gambar 5: Pengemasan \& Pelabelan Produk

3. Pelatihan Proses Pemasaran, Model Pemasaran, Etika Pemasaran, Tips dan Trik Keberhasilan dalam pemasaran.

4. Diskusi tentang Keuntungan dan Hambatan dalam Dunia Bisnis.

\section{KESIMPULAN}

Kegiatan pengabdian yang dilakukan oleh tim dosen dan mahasiswa Fakultas Ekonomi Universitas Muhammadiyah Sorong yang dilaksanakan pada tanggal 17 Desember 2021 dikantor Kelurahan Malagusa yang beralamatkan di jalan Cempedak Kabupaten Sorong yang telah dihadiri oleh 20 peserta yang terdiri dari ibu - ibu rumah tangga warga setempat. Warga setempat sangat antusias dalam mengikuti pelatihan pengelolahan ubi ungu hal ini terlihat dari jumlah kehadiran masyarakat, dimana semua warga yang hadir mereka menjadi target dalam kegiatan pelatihan, masyarakat mengikuti acara dari awal sampai akhir serta sangat antusias dalam sesi bertanya, diskusi maupun sharing. Dalam pelaksanaan kegiatan Pengabdian Masyarakat di Kelurahan Malagusa Kabupaten Sorong sudah terlaksanakan. Selain itu, kegiatan pelatihan yang telah dilakukan yaitu untuk memberikan kreativitas dan keterampilan kepada warga setempat tentang pengolahan ubi ungu menjadi olahan makanan yaitu donat, memberikan penguatan materi dan berdiskusi dengan warga terkait pelatihan, manajemen pemasaran serta motivasi berwirausaha serta mendampingin para warga dalam melakukan proses produksi, pengemasan, pelabelan, desain label dan pelabelan, kemudian melakukan evaluasi antara tim pengabdian masyarakat dengan warga yang telah mengikuti kegiatan pelatihan. 


\section{REFERENSI}

Anna, L. (2016, 09 06). Pengertian Ubi Ungu. Diambil Kembali Dari Https://Health.Kompas.Com/Read/2016/09/06/070600323/Ubi.Ungu.Pangan.Lokal.Kay a.Antioksidan

Husni Muharram R.BA., M. D. (2018). Manajemen Pemasaran Konsep Dan Strategi. Semarang: Cv.Manhaji.

Kumawula. (2019). Pelatihan Pemasaran Produk Olahan Telo Ungu Di Desa. Kumawula, Vol. 2, No.1, April 2019, Hal 1 - 11, 11.

Lewenussa, R., et al. (2019). Pelatihan Fitur Project Dengan Sofware Accurate Pada Mahasiswa Program Studi Manajemen Dalam Rangka Peningkatan Produktifitas Dan Keterampilan Mahasiswa Dalam Dunia Kerja. Abdimas: Papua Journal of Community Service, 1(2), 31-44.

Prasetyo, B. D., et al. (2021). Pelatihan Strategi Bersaing Sumber Daya Manusia Di Era 5.0 Pada Masyarakat Desa. Jurnal PADMA: Pengabdian Dharma Masyarakat, 1(4).

Rawi, R. D. P., et al. (2019). Pelatihan Pembuatan Keripik Pisang Sebagai Sarana Peluang Bisnis Dan Kreatifitas Mahasiswa Fakultas Ekonomi Universitas Muhammadiyah Sorong. Abdimas: Papua Journal of Community Service, 1(2), 24-30.

Tjiptono, Fandi. 1996. Strategi Pemasaran. Edisi Kedua. Penerbit Andy, Yogyakarta. 